\title{
Áreas naturales protegidas en el litoral argentino: un análisis comparativo de las regulaciones vigentes
}

Protected natural areas on the Argentine Littoral Region: a comparative analysis of current regulations

\author{
Sabrina Adamik ${ }^{1}$ \\ Universidad Católica de Santa Fe, Argentina \\ M. Valeria Berros ${ }^{2}$ \\ Universidad Nacional del Litoral, Argentina
}

Revista Derechos en Acción ISSN 2525-1678/ e-ISSN 2525-1686

Año 6/Nº 19 Otoño 2021 (21 marzo a 20 junio), 410-436

DOl: https://doi.org/10.24215/25251678e522

Recibido: 07/04/2021

Aprobado: 15/05/2021

Resumen: En este artículo intentamos reponer el estado de situación de las principales regulaciones provinciales en parte de la región del litoral argentino. En particular, se analizan los casos de Santa Fe, Entre Ríos, Corrientes y Misiones en materia de áreas naturales protegidas como estrategia para la tutela de la biodiversidad. Para ello se presentan, en cuatro apartados que poseen una estructura simétrica, los siguientes

\footnotetext{
1 Abogada Universidad Católica de Santa Fe, Argentina. Email: sabrinaadamik@hotmail.es (ORCID: https://orcid.org/0000-0002-0471-9018).

2 Doctora en Derecho UNL, Investigadora CONICET, Profesora UNL y UCSF, Former Fellow Rachel Carson Center for Environment \& Society de la Universidad de Münich. Este trabajo resulta del proyecto de investigación "Aportes para repensar el derecho ambiental del litoral argentino" en ejecución en la Facultad de Derecho y Ciencia Política de la Universidad Católica de Santa Fe. valeria.berros@outlook.com (ORCID: https://orcid.org/0000-0002-9472-5955).
} 
temas: 1) Una breve presentación de los principales ecosistemas que posee cada provincia, 2) Un análisis sobre el contenido constitucional que puede ser asociado a este tema conforme las cartas magnas vigentes en cada territorio, 3) Una presentación de las normas provinciales que regulan los sistemas de áreas naturales protegidas, 4) Una breve aproximación al resultado protectorio en términos territoriales. Finalmente, se plantean una serie de interrogantes en relación a algunas agendas abiertas y posibles desafíos para repensar esta estrategia de tutela desde recientes debates al interior del campo jurídico contemporáneo.

Palabras clave: Biodiversidad, Derecho Ambiental, Región Litoral, Áreas Naturales Protegidas

Abstract: This article aims to review the state of the art of the main provincial regulations in part of the Argentinean littoral region. In particular, the cases of Santa Fe, Entre Ríos, Corrientes and Misiones are analyzed with regard to natural protected areas as a strategy for the protection of biodiversity. The following topics are presented in four symmetrically structured sections: 1) a brief presentation of the main ecosystems in each province, 2) an analysis of the constitutional content that can be associated with this issue in accordance with the constitution of each territory, 3) a presentation of the provincial norms that regulate the systems of natural protected areas, 4) a brief approximation of the protective result in territorial terms. Finally, a series of questions are posed in relation to some open agendas and possible challenges to rethink this protection strategy from recent debates in the contemporary legal field.

Keywords: Biodiversity, Environmental Law, Littoral Region, Natural Protected Areas

\section{Introducción}

La Plataforma Intergubernamental sobre Diversidad Biológica y Servicios de los Ecosistemas (IPBES) es un organismo independiente que se conforma por expertos y expertas de diversas latitudes del mundo y viene alertando, junto a otras organizaciones de diferente escala territorial y perfil de trabajo, 
sobre el grave estado de la biodiversidad a escala planetaria. ${ }^{3}$ En 2019, su informe anual, afirmó que la tasa de extinción se había acelerado de forma inédita. Ello implica una erosión constante de las condiciones de existencia de los seres vivos dado que la pérdida de diversidad biológica posee derivas muy heterogéneas, algunas más visibles que otras. En 2020 la pandemia Covid-19 visibilizó de modo trágico y concluyente que la necesidad de preservar los ecosistemas es central: arrasar con ellos genera consecuencias que pueden adquirir, incluso, esta dimensión que hoy experimentamos en todo el planeta. A ello pueden sumarse los graves incendios que afectaron esta zona del litoral argentino con gravedad durante el mismo año y que dejaron en clara la fragilidad de los ecosistemas ante actividades antrópicas, especialmente aquellas ilegales.

La importancia de la tutela de los ecosistemas se tradujo tempranamente en el campo jurídico y la Declaración de Estocolmo de 1972, resultado de la Conferencia de Naciones Unidas sobre el Medio Ambiente Humano, constituye un documento central en la identificación de la problemática y en la historia del derecho ambiental. El tema específico de la pérdida de biodiversidad adquiere centralidad algunas décadas más tarde bajo esa denominación, en particular en los años noventa. En este momento comienza a tener un rol medular en la discusión de varias disciplinas y al interior del derecho internacional se sella el texto del Convenio sobre la Diversidad Biológica en 1992. Argentina ratifica dicho convenio dos años más tarde y, además, introduce la tutela de la biodiversidad y del patrimonio natural en el artículo 41 incorporado en la reforma constitucional de 1994.

Existen diferentes herramientas jurídicas para organizar su protección. Una de ellas consiste en la creación de áreas naturales protegidas que, cabe señalar, son configuraciones previas a las normativas internacionales mencionadas. Hacia fines del siglo XIX primero en Estados Unidos y luego en diferentes

3 Sitio web oficial: https://www.ipbes.net/ 
países, dentro de los cuales se enrola Argentina desde inicios del siglo XX, se comienzan a incorporar las ideas de parques nacionales, áreas naturales protegidas, monumentos naturales. Estos procesos se asocian en numerosos casos a la ampliación de fronteras, lo que en reiteradas experiencias también se vincula a una serie de conflictos con pueblos indígenas y con países limítrofes. En la actualidad constituyen una de las principales herramientas para la protección de los ecosistemas aunque se está revisando, desde diversas disciplinas, la diferenciación entre territorio humano y no humano, a los fines de configurar otro tipo de estrategias que se desmarcan de esa lógica binaria. ${ }^{4}$

Sin perjuicio de la centralidad que adquieren este tipo de estrategias para la conservación, lo cierto es que desde el campo jurídico argentino es bastante menor la atención asignada a este tema si se compara con la producción de conocimiento vinculada a otros aspectos del derecho ambiental contemporáneo. Ello se profundiza cuando se trata de identificar análisis sobre normas provinciales. Es por ello que este trabajo pretende realizar una contribución mediante un estudio sobre un sector del litoral argentino que cuenta con algunos de los ecosistemas con mayor biodiversidad de nuestro territorio: las provincias de Misiones, Entre Ríos, Corrientes y Santa Fe.

La metodología a los efectos de realizar el presente análisis se basa en herramientas que se corresponden con una estrategia cualitativa que aborda una serie de unidades informantes entre las que se destaca la normativa de los diferentes espacios regulatorios, informes estatales y de expertos y documentos de organizaciones no gubernamentales. Una vez configurado el corpus de documentos recurrimos al análisis clásico de documental: análisis de contenido. Para ello se construyeron una serie de instrumentos adecuados para cada tipo de documento a los fines de sistematizar datos, posibilitando su correlación y su posterior procesamiento.

\footnotetext{
4 FERRERO, Brian, (2018). "Tras una definición de las Áreas Protegidas. Apuntes sobre la conservación de la naturaleza en Argentina", Revista Universitaria de Geografía.
} 
La indagación sobre estos documentos se encuentra inspirada en una serie de preguntas entre las que se destacan: ¿Cúal es el contenido y las particularidades que estas normas poseen? ¿Qué características las articula y cuáles las diferencia? ¿Son adecuadas a la actualidad que exige un conjunto de políticas públicas robustas, participativas y efectivas, así como diseños institucionales apropiados? Estos interrogantes, entre otros, poseen hoy mayor relevancia, no solo para la conservación de la variabilidad de especies sino también para la lucha contra el cambio climático y, en cada vez más numerosas ocasiones, para proteger comunidades humanas amenazadas.

En este artículo intentamos reponer cual es el estado de situación sobre esta temática en las mencionadas provincias cuyas principales normativas en la materia son objeto de análisis. Para ello se presentan en cuatro apartados que poseen similar estructura los siguientes temas: 1) ¿Cuáles son los ecosistemas que existen en cada territorio provincial?, 2) ¿La Constitución provincial en vigor contiene alguna previsión sobre el tema?, 3) ¿Existe normativa específica sobre áreas naturales protegidas?, 4) ¿Cuál es el resultado protectorio preliminar que se visualiza en cada provincia conforme los datos oficiales?

\section{Provincia de Santa Fe}

\section{II.1. Los ecosistemas de la Provincia de Santa Fe}

En Santa Fe existen nueve áreas naturales protegidas a lo que cabe añadir las áreas naturales municipales y privadas. ${ }^{5} \mathrm{~A}$ su vez, hace años se intenta generar un puente entre este concepto y la necesidad de representar las diferentes ecorregiones o regiones ambientales que se definen en base a criterios físicos y biológicos que enfocan en las condiciones del clima, el suelo, el régimen hidrológico así como las características de la flora y

5 Ambiente y Cambio Climático (2021). "Reservas de dominio público". Disponible en: https://www.santafe.gov.ar/index.php/web/content/view/full/208258/(subtema)/112853 
de la fauna. ${ }^{6}$ Se identifican seis regiones ambientales: la Cuña Boscosa, los Bajos Submeridionales, el Chaco Semiárido, la Zona Transicional, la Pampa Húmeda y el Valle del Río Paraná.

- Cuña Boscosa: esta zona introduce una formación arbórea del parque chaqueño en forma de cuña en el norte del territorio provincial, por su inclinación hacia el sur opera como área de escurrimiento a través de arroyos y otros cursos de agua. La flora que la caracteriza es el quebracho y algarrobo y entre la fauna se destacan pumas, zorros, y guazunchos.

- Bajos Submeridionales: esta zona se encuentra en el centro norte provincial en el que se identifican numerosas superficies de agua que constituyen un área estratégica para un importante número de especies.

- Chaco Semiárido: esta zona se encuentra en el Departamento 9 de Julio próximo a la frontera con Santiago del Estero. Debido a la escasez de lluvias la flora predominante son árboles y arbustos adaptados a dicha situación como el quebracho colorado y blanco, guayacán, palmeras entre otras especies. En relación a la fauna se destacan las iguanas, pecaríes y oso hormiguero.

- Zona transicional: esta zona se ubica en el centro de la provincia y presenta características de sus zonas aledañas al norte y al sur. Se caracteriza por sus pastizales y pajonales y por animales como zorros, lechuzas y armadillos.

- Zona Pampeana: es el área al sur del río carcarañá que posiblemente sea la que más transformaciones ha sufrido debido a la producción agrícola-ganadera. En los últimos años este cambio se ha intensificado por los procesos de agriculturización extrema con alta incidencia del monocultivo.

6 BIASSATI, Néstor (2016). Las ecoregiones. Su conservación y las áreas naturales protegidas en Santa Fe. Ministerio de Ambiente Santa Fe. Disponible en: https://www.santafe.gov.ar/ index.php/web/content/download/229660/1202209/file/LIBRO\%20ECOREGIONES_web.pdf 
- Valle del río Paraná: es la superficie que, a lo largo de toda la provincia, se encuentra con el río Paraná y se configura como un ambiente asociado a islas y arroyos que forman parte de dicho ecosistema. La región se caracteriza por el cambio permanente debido a las crecientes y bajantes del río y presenta una gran riqueza en términos de especies de plantas y de animales como nutrias, yacarés, capibaras, dorado, y surubí.

\section{II.2. La Constitución santafesina}

La provincia de Santa Fe ha sancionado su constitución el 14 de abril de 1962 y en la misma no se ha hecho referencia específicamente a las áreas naturales protegidas. Sin embargo, el artículo 28 coloca cierto énfasis sobre los recursos naturales.

Un análisis de su redacción permite distinguir dos partes: una primera mirada centrada en el humano como quien usa y goza de la tierra a partir de la promoción y estímulo de su trabajo, así como mediante su explotación racional conforme a la función social de la propiedad, entre otros aspectos. Y una última parte de su texto que enfatiza en la forma de conservación de los recursos naturales: "La Provincia...protege el suelo de la degradación y erosión, conserva y restaura la capacidad productiva de las tierras y estimula el perfeccionamiento de las bases técnicas de su laboreo. Resguarda la flora y la fauna autóctonas y proyecta, ejecuta y fiscaliza planes orgánicos y racionales de forestación y reforestación...". (Const., 1962, art. 28)

Este último párrafo, desde una interpretación dinámica de su contenido, podría ser considerado como fundamento constitucional de las áreas naturales protegidas en la provincia.

\section{II.3. El sistema provincial de áreas naturales protegidas}

Gran parte de las áreas protegidas de Santa Fe fueron creadas entre 1963 y 2003 sin un marco legal específico. Estas 
áreas no contaban con objetivos definidos ni planes de manejo y fueron generadas con el fin de ser conservadas con la menor intervención humana posible. En 1991 se crean las reservas privadas de usos múltiples a través del Decreto 0961 y se fueron conformando varias reservas dentro de esta categoría. Estos antecedentes fueron gestando la necesidad de crear un marco regulatorio lo que redundó en la posterior sanción de la Ley 12.175 de 2003 que establece el sistema provincial de áreas naturales protegidas.

Esta última ley define a las áreas naturales protegidas como: "todo ambiente o territorio que, manteniendo su aspecto original sin alteraciones importantes provocadas por la actividad humana, esté sujeta a un manejo especial legalmente establecido y destinado a cumplir objetivos de conservación, protección y/o preservación de su flora, fauna, paisaje y demás componentes bióticos y abióticos de sus ecosistemas" (Ley 12.175, 2003, art. 3) e instaura ocho categorías de manejo:

1) Reserva Natural Estricta o Reserva Científica calificadas como "las áreas naturales con ecosistemas acuáticos o terrestres, elementos y/o especies de flora y fauna de importancia científica provincial. Estas áreas revestirán carácter perpetuo. En ellas los procesos se desarrollarán sin interferencia humana directa, aún cuando puedan darse fenómenos de alteraciones naturales como incendios espontáneos, invasión de plaga entre otros, excepcionalmente la Autoridad de Aplicación determinará la necesidad de intervención cuando los estudios técnicos así lo aconsejen." (Ley 12.175, 2003, art. 23)

2) Parques Provinciales: "ecosistemas con representatividad biogeográfica, poco alterados por la actividad u ocupación humana, que contienen especies de flora y fauna, sitios geomorfológicos y/o paisajes de interés científico, educativo y recreativo" (Ley 12.175, 2003, art. 27). Para su mejor administración se dividen en (i) Zonas intangibles: "son aquellas poco afectadas por la actividad humana, que 
contengan ecosistemas y especies de flora y fauna, en los cuales los procesos ecológicos han podido seguir su curso espontáneo o con un mínimo de interferencia humana" (Ley 12.175, 2003, art. 29) y (ii) Zonas restringidas: "poseen las mismas características que las anteriores, pero podrán ser utilizadas por la Autoridad de Aplicación en atención al turismo, actividades educativas, de estudio, entre otras" (Ley 12.175, 2003, art. 32)

3) Monumentos Naturales: "sitios, entidades biológicas, ambientes naturales y yacimientos arqueológicos y paleontológicos de relevante y singular importancia científica, estética o cultural, declarados como tales por normas especiales y a las cuales se le acuerda protección absoluta. Son inviolables, no pudiendo realizarse en ellos actividades algunas con excepción de visitas guiadas que garanticen el principio de intangibilidad absoluta, inspecciones oficiales o investigaciones científicas permitidas por la Autoridad de Aplicación con relación a los objetivos de conservación establecidos para el caso" (Ley 12.175, 2003, art. 35)

En el año 2003 se sanciona la Ley 12.182 que declara como monumentos naturales al Aguará Guazú y al Venado de las Pampas. Luego de ello se han presentado proyectos de ley con el fin de declarar como tales, por ejemplo, al águila coronada y al cardenal amarillo.

4) Reserva Natural Manejada o Santuario de Flora y Fauna: "áreas destinadas a preservar lugares o hábitat específicos indispensables para mantener la existencia de poblaciones de especies de importancia para la conservación o para el uso sustentable de los grupos locales. Podrá ser necesario algún tipo de manipulación del ambiente para crear las condiciones de vida óptima para las especies o la comunidad destinataria de la preservación, en lo posible respetando aquellos elementos del ecosistema que se privilegien en los objetivos de la creación de la reserva" (Ley 12.175, 2003, art. 37) 
5) Paisaje Protegido: "ambientes naturales o seminaturales, con valores culturales dignos de ser preservados en su condición tradicional o actual, siempre que no sean netamente urbanos" (Ley 12.175, 2003, art. 39)

6) Reservas Naturales Culturales: "áreas habitadas por sociedades tradicionales interesadas a preservar pautas culturales propias y cuya relación armónica con el medio ambiente es necesario garantizar; así como las que presenten valores antropológicos y/o históricos, con fines científicos o educativos" (Ley 12.175, 2003, art. 41)

7) Reservas Privadas de Uso Múltiple: "presentan ciertos grados de transformación en su condición natural, mantienen un sistema ecológico en dinámico equilibrio, amalgaman la presencia y actividad productiva del hombre con la supervivencia de ambientes naturales y sus recursos silvestres, necesitan un régimen regulador que garantice el armónico desarrollo y conservación de su potencialidad productiva, vida silvestre y paisaje; y por su importancia o interés científico, agrario, económico y cultural, se declaren bajo el control y fiscalización técnica del Estado Provincial” (Ley 12.175, 2003, art. 43)

8) Reservas Hídricas o Humedales: "aquellas que poseen cuencas de captación o reservorios hídricos, insertos en ambientes silvestres, que califique su especial significación ecológica y turística; y/o que sean declaradas como tal" (Ley 12.175, 2003, art. 48)

Todas estas áreas naturales deben contar con un Plan de Manejo, es decir, un instrumento fundamental de planificación y ordenamiento espacial que define y coadyuva a la gestión y conservación del área, contiene las directrices, lineamientos y políticas para su administración, modalidades de manejo, asignaciones de usos y actividades permitidas en base a un diagnóstico, base para la zonificación y los objetivos de gestión y estrategia del territorio que se busca proteger. 


\section{II.4. Territorio protegido}

Si nos preguntamos cual es el porcentaje de superficie de las áreas naturales protegidas que tiene esta provincia con relación a su territorio total, los datos no son alentadores debido a que se calcula que sólo el $0,1324 \%$ se encuentra protegido bajo este sistema. Este dato surge del Primer Seminario sobre áreas naturales protegidas de la provincia de Santa Fe realizado en el año 2008 entre la Universidad Nacional del Litoral y la entonces Secretaría de Ambiente y Desarrollo Sostenible de la Provincia. ${ }^{7}$ El porcentaje no ha variado de forma significativa en los últimos años, con lo cual Santa Fe no solo es una de las provincias del litoral con menos superficie de áreas naturales protegidas, sino que se trata de uno de los territorios con menor superficie protegida del país.

En el territorio santafesino podemos encontrar áreas naturales de dominio público y de dominio privado. Las primeras son de propiedad del Estado; las privadas están a cargo de particulares que efectuán diferentes convenios con el Ministerio de Medio Ambiente y Cambio Climático.

Son áreas naturales de dominio público, en carácter de reservas naturales estrictas o reservas científicas, las siguientes: Reserva La Loca ubicada en la ecoregión Chaco Húmedo; Reserva Virá Pitá localizada en la misma región; y la Reserva del Medio-Los Caballos que comprende la Isla del Medio y el Islote Los Caballos, próximos al río Paraná. A ellas se suma el parque provincial Cayastá ubicado en el Valle del río Paraná y dos reservas naturales manejadas: Potrero Lote $7 \mathrm{~b}$ situado al norte de la provincia compuesto principalmente por un sector de bosques típicos de la región geográfica del Chaco y El Fisco en el departamento de San Cristóbal. Finalmente, se identifican dos reservas hídricas y un paisaje protegido. En el primer caso se trata de Arroyo Saladillo en el sur provincial y Arroyo Sauce-Pavón

\footnotetext{
7 Para más información consultar en: https://www.unl.edu.ar/noticias/news/view/se_desarroll\%C3\%B3_el_seminario_sobre_\%C3\%A1reas_naturales_protegidas\#.YFpLIVVKjct
} 
creado en concomitancia con el anterior y bajo los mismos criterios. Finalmente, existe un paisaje protegido como Corredor Biológico de la autopista provincial AP-01 Rosario-Santa Fe que pasó de ser una creación asociada al sistema de concesión de la autopista a ser un paisaje protegido a partir de 2014 .

A estas áreas se agregan aquellas que pertenecen al dominio privado. En calidad de reservas privadas de usos múltiples se identifica Isleta Linda ubicada en el norte provincial; y Federico Wildemurth, la Noria, Estancia Santa Catalina y La Elena que se encuentran en diferentes latitudes de la zona central de Santa Fe.

\section{III.Provincia de Entre Ríos}

\section{III.1. Los ecosistemas de la Provincia de Entre Ríos}

El territorio de la Provincia de Entre Ríos abarca una significativa biodiversidad. Cuatro de las dieciocho ecorregiones o regiones naturales de nuestro país, confluyen en Entre Ríos: Espinal, Pampa, Delta e Islas del Paraná y un pequeño segmento de los Esteros del Iberá. ${ }^{8}$

- Delta e Islas del Paraná: comprende los valles de inundación de la parte media e inferior de los ríos Paraná y Paraguay y se caracteriza por la presencia de montes, pajonales y lagunas que incorporan aspectos típicos de la selva misionera. Abundan animales como carpincho, yacaré, ciervo de los pantanos, lobito de río, nutria.

- Espinal: zona caracterizada por la presencia de sabanas y pastizales de gramíneas que, de a poco, van desapareciendo debido al avance de la agroindustria, y en el que se identifican tres subregiones: el Espinal del Ñandubay, el Espinal de los Algarrobos y el Espinal del Caldén. Abundan el puma, zorro gris pampeano, comadrejas, hurón, vizcacha.

8 Dirección Hidráulica de Entre Ríos. Dpto. de Hidrología y Ordenamiento de Cuencas. (2019) Eco-Regiones, Biodiversidad y Áreas Protegidas de Entre Ríos. CGE-Dirección de Planeamiento Educativo. Programa de Educación Ambiental. 
- Pampa: esta ecoregión se extiende desde el centro hacia el sur, y limita en el extremo norte de su distribución con el Espinal y en el extremo sur con el Delta e Islas del Paraná.

- Esteros del Iberá: solo una pequeña porción de esteros se puede visualizar en la provincia de Entre Ríos.

\section{III.2. La Constitución entrerriana}

La reforma constitucional de Entre Ríos del año 2008 incorporó el artículo 22 que reconoce el derecho a un ambiente sano, siguiendo un tratamiento y esquema similar al del artículo 41 de la Constitución Nacional: "Todos los habitantes gozan del derecho a vivir en un ambiente sano y equilibrado, apto para el desarrollo humano, donde las actividades sean compatibles con el desarrollo sustentable, para mejorar la calidad de vida y satisfacer las necesidades presentes, sin comprometer la de las generaciones futuras. Tienen el deber de preservarlo y mejorarlo, como patrimonio común" (Const. 2008, art. 22).

A su vez, el texto constitucional incorpora una referencia específica sobre ciertos ecosistemas: “... El Estado asegura la gestión sustentable y la preservación de los montes nativos, de las selvas ribereñas y de las especies autóctonas, fomentando actividades que salvaguarden la estabilidad ecológica. El propietario de montes nativos tiene derecho a ser compensado por su preservación..." (Const. 2008, art. 85) así como afirma que “... los humedales se declaran libres de construcción de obras de infraestructura a gran escala que puedan interrumpir o degradar la libertad de sus aguas y el desarrollo natural de sus ecosistemas asociados..." (Const. 2008, art. 85).

En este mismo artículo se incorpora una referencia directa al tema que nos ocupa dado que se establece que “... El Estado propicia por ley la creación de áreas protegidas, sobre la base de estudios técnicos. Reconoce el derecho de sus propietarios a recibir compensaciones económicas y exenciones impositivas, en su caso..." (Const. 2008, art. 85) con lo cual el sistema de 
áreas naturales protegidas de la provincia cuenta con un fundamento constitucional explícito.

\section{III.3. El sistema provincial de áreas naturales protegidas}

Conforme el texto constitucional citado, la provincia de Entre Ríos propicia la creación de áreas naturales protegidas mediante la sanción de leyes especiales y reconoce el derecho a compensaciones económicas. Si bien la constitución data de 2008, es en 1995 que se organiza legalmente el Sistema Provincial de Áreas Naturales Protegidas provincial a través de la Ley 8967.

En el año 2017 se deroga la ley de 1995 y se sanciona la Ley 10.479. En su artículo 1 se establece que el sistema se integra por todas las áreas ya sea de dominio público o privado. La ley contempla siete categorías de manejo en su artículo 8:

1) Parques Naturales: "son las áreas no afectadas por la actividad humana, que tienen una determinada representatividad biográfica y significación ecológica. Constituyen unidades ecológicas suficientemente extensas, que poseen elementos de especial importancia de la flora y fauna, con una singular y notable belleza paisajística. Los mismos son declarados por la autoridad pública, básicamente intangibles, de estricta protección y rigurosa preservación de la naturaleza y con uso restringido de sus ambientes silvestres" (Ley 10.479, 2017, art. 9). Estos se dividen en zonas intangibles y zonas protegidas según la afectación o no por actividad humana.

2) Monumentos Naturales: "Son áreas que contengan elementos naturales de notable importancia, especies vivas de animales o vegetales; formaciones geológicas de valor histórico, científico, estético y educativo, cuya existencia podría estar amenazada" (Ley 10.479, 2017, art. 17). En Entre Ríos seis especies han sido declaradas como tales: ciervo de los pantanos y aguará guazú (Resolución 852 de 
la Dirección General de Recursos Naturales), el federal y el cardenal azul (Resolución 851 de la Dirección General de Recursos Naturales), el cardenal amarillo (Decreto 4933) y el tordo amarillo (Decreto 5942).

3) Reservas Naturales Culturales: "Son aquellas en las que se encuentran comunidades aborígenes u otras, interesadas en preservar determinadas pautas culturales propias y cuya relación armónica con el medio es necesario garantizar y las que albergan yacimientos arqueológicos o cualquier otra referencia histórica de interés" (Ley 10.479, 2017, art. 20).

4) Reservas de Usos Múltiples: "Las zonas que determinadas por estudios preliminares, sean apropiadas para la producción maderera, hídrica, agrícola y ganadera sustentables, a las que posean flora y fauna silvestre, autóctona y que constituyan formas de esparcimiento al aire libre..." (Ley 10.479, 2017, art. 22).

5) Paisajes Protegidos: "Son paisajes naturales, seminaturales y de carácter cultural, dignos de ser preservados en su condición tradicional o actual" (Ley 10.479, 2017, art. 24). En esta categoría se distinguen las zonas aprovechadas por el humano de manera intensiva para esparcimiento y turismo y los paisajes que, por ser resultado de la interacción entre las personas y la naturaleza, reflejan manifestaciones culturales como sitios sagrados, etc.

6) Reservas Naturales Estrictas: "Es un área que posee algún ecosistema, rasgo geológico, fisiográfico, especies o taxones destacadas o representativas, destinada principalmente a actividades de investigación científica y monitoreo ambiental. El área propuesta debe estar considerablemente exenta de intervención humana directa y ser capaz de permanecer en esas condiciones" (Ley 10.479, 2017, art. 26).

8) Reservas ícticas: "Es todo ambiente acuático que constituya zona de cría, desove o de concentración de cardúmenes, singularmente calificado para estas finalidades y a aquellos otros ambientes que se consideren especialmente 
merecedores de protección por sus valores de conservación para los peces autóctonos. Las reservas ícticas están sometidas a regímenes especiales de manejo, pudiendo establecerse vedas parciales o absolutas para la pesca" (Ley 10.479, 2017, art. 27).

\section{III.4. Territorio protegido}

En el territorio entrerriano podemos encontrar varias áreas naturales protegidas públicas y privadas, aunque es escasa la información oficial que pueden obtenerse sobre parte de ellas. Para el año 2020 se calcula que la Provincia cuenta con 1.600.000 hectáreas de áreas naturales protegidas lo que representa alrededor del $20 \%$ del territorio involucrando en este cómputo no sólo las áreas naturales protegidas públicas y privadas sino también sus dos sitios Ramsar.?

Existe un importante número de áreas naturales provinciales sin perjuicio de lo cual la información accesible sólo se remite a la normativa de creación de cada una de ellas. Dentro del ámbito público, por ejemplo, se identifican Parque del Río Uruguay, La Vizcachita, Monte de la Paloma, Paraná Medio, Jardín Botánico Oro Verde, Parque Escolar Rural Enrique Berduc/ CGE, Laguna del Pescado y vías de comunicación con el Río Victoria, Río Gualeguaychú (desde su nacimiento hasta desembocadura en Río Uruguay). Como áreas de dominio público-privado se enumeran El Gato y Lomas Limpias, Reserva de los Pájaros y sus Pueblos Libres y Humedales Victoria. A su vez, se encuentra un registro de áreas naturales protegidas de dominio privado compuesto por El Potrero, El Carayá, Don Sebastián, La Aurora del Palmar, Santa Rosa, El Guayabo y El Cencerro. Es importante señalar que la información de acceso

9 Secretaría de Comunicación Provincia de Entre Ríos (2020) “La provincia creó el mapa de Áreas Naturales Protegidas para la preservación de los ecosistemas". Disponible en: https:// noticias.entrerios.gov.ar/notas/la-provincia-cre-el-mapa-de-reas-naturales-protegidas-parala-preservacin-de-los-ecosistemas.htm 
público existente torna dificultoso conocer sobre el estado de conservación de cada área.

\section{IV.Provincia de Corrientes}

\section{IV.1. Los ecosistemas de la Provincia de Corrientes}

La Provincia de Corrientes alberga una gran diversidad biológica y es posible reconocer cinco ecorregiones ${ }^{10}$ :

- Deltas e Islas del Paraná: se caracteriza por presentar un conjunto de islas bajas e inundables, delimitadas por los cauces principales de los ríos Paraná y Paraguay.

- Esteros del Iberá: esta ecorregión es la más extensa en la provincia de Corrientes, ocupando el centro norte de la misma. El ecosistema consiste en lagunas, esteros y bañados, separados por cordones arenosos.

- Espinal: como ya fue nombrado en las anteriores provincias, el espinal es una ecorregión de la llanura chaco-pampeana que, en este caso, abarca el sur de la provincia.

- Campos y Malezales: es la zona ubicada al este de Corrientes y al suroeste de Misiones y se caracteriza por amplios pastizales de llanura de relieve ondulado.

- Chaco Húmedo: se trata de un territorio con suave pendiente en el que predominan ambientes deprimidos en el noroeste correntino.

\section{IV.2. La Constitución de Corrientes}

La última constitución de Corrientes data del año 2007 y reconoce que "Toda persona tiene el derecho a gozar de un ambiente sano y equilibrado y el deber de preservarlo para las generaciones presentes y futuras" (Const. 2007, art. 49).

\footnotetext{
10 Para ampliar información puede consultarse: FONTANA, José (2013). "Las ecorregiones de Corrientes y sur de Misiones" en /l Simposio de Restauración Ecológica en Argentina: enfoques y prioridades.
} 
A continuación, afirma que cualquier habitante tiene derecho a acceder a la información sobre el impacto que las actividades causen en el ambiente y a participar en los procesos de toma de decisiones. También se otorga al Estado Provincial fijar las políticas ambientales, proteger y preservar la integridad del ambiente, el uso y la administración racional de los recursos naturales. A su vez, se considera que es deber del estado estimular e impulsar la investigación y ejecución de proyectos fundados en planes y programas de desarrollo sustentable, con previa realización de una evaluación del impacto ambiental.

Si bien no existe una referencia especialmente ligada al concepto de áreas naturales protegidas sí se regula la necesidad de resguardar la biodiversidad y el control de los recursos genéticos (Const. 2007, art. 65) así como se incluye en el pacto constitucional una norma sobre uno de los principales ecosistemas provinciales: "Se declara patrimonio estratégico, natural y cultural de la Provincia de Corrientes a los fines de su preservación, conservación y defensa: el ecosistema Iberá, sus esteros y su diversidad biológica, y como reservorio de agua dulce, en la extensión territorial que por ley se determine, previo relevamiento y fundada en estudios técnicos. Debe preservarse el derecho de los pobladores originarios, respetando sus formas de organización comunitaria e identidad cultural" (Const. 2007, art. 66)

\section{IV.3. El sistema provincial de áreas naturales protegidas}

El ordenamiento jurídico de Corrientes contiene la Ley 4.736 de 1993, un tanto distinta a las que hemos presentado con anterioridad que, además, son más contemporáneas. Esta ley reconoce tres categorías de áreas naturales protegidas:

1) Parque Provincial: "gozarán de protección absoluta por lo que deberán conservarse en su estado natural, sin más alteraciones que las necesarias para su control y atención del visitante. Queda prohibido en ellos toda clase de actividad susceptible de provocar modificaciones. Las actividades 
relacionadas con el turismo y la pesca deportiva, solo podrán realizarse con sujeción a las reglamentaciones que dicte la autoridad de aplicación" (Ley 4736, 1993, art. 5).

2) Monumento Natural: "cosas, especies vivas de animales o plantas, que, por su interés estético, valor histórico o científico, se les acuerde protección absoluta. Serán inviolables, no pudiendo realizarse en ellos o respecto de ellos actividad alguna, excepto las necesarias para su cuidado, investigación científica o inspecciones oficiales permitidas por la autoridad de aplicación" (Ley 4736, 1993, art. 7). El Decreto 1555 de 1992 declaró como tales al ciervo de los pantanos, lobito de río, aguará guazú y ciervo de los pantanos. Años más tarde, se suma el oso hormiguero grande y el yaguareté a la lista de monumentos naturales correntinos.

3) Reserva Natural: "gozarán de protección parcial y constituirán zonas circundantes o de transición con los Parques Provinciales. En ellas tendrán prioridad a todo otro interés, la conservación de la flora y fauna autóctonas, las bellezas panorámicas y el equilibrio de sus ecosistemas" (Ley 4736, 1993, art. 8).

A su vez, en el artículo 12 de la ley crea el Parque Provincial Iberá a lo que luego va a sumarse, en el año 2000, la creación de la Reserva Natural Iberá mediante Ley 3.771.

\section{VI.4. Territorio protegido}

En la provincia de Corrientes, "la conservación en tierras privadas abarca alrededor de $1.863 \mathrm{~km} 2$, mientras que las áreas protegidas públicas totalizan $8.086 \mathrm{~km} 2 " 11$, lo cual implica alrededor de un $12 \%$ de territorio protegido. Con la Reserva Natural del Iberá, sucede algo particular ya que el dominio de

\footnotetext{
11 El Litoral (2018) "Áreas Protegidas: relevaron la eficiencia de las reservas naturales privadas". Disponible en: https://www.ellitoral.com.ar/corrientes/2018-5-31-11-45-0-areasprotegidas-relevaron-la-eficiencia-de-las-reservas-naturales-privadas
} 
la tierra es mixto, porque coexisten propiedades privadas y fiscales. Esta reserva fue creada en el año 1983 y abarca 1.300 .000 hectáreas. En su interior se ubica el Parque Provincial Iberá sobre tierras públicas, el cual a su vez está rodeado por tierras de propiedad privada que conforman la reserva provincial. A ello se suma la más reciente creación del Parque Nacional Iberá en 2018.

A este parque provincial/nacional puede agregarse la reserva natural Laguna Brava, el Parque Provincial San Cayetano, entre otros. Además, es importante señalar que, en esta provincia, en el año 1984, se declaró zona de reserva de fauna a todas las islas e islotes, ríos, riachos, arroyos y todo curso de agua ubicado al oeste del Departamento Goya. Por su parte, la Ley 4827 de 1994 declaró Zonas de Reserva de fauna íctica, en la jurisdicción de aguas territoriales que corresponden a la Provincia de Corrientes, a los tramos del Río Paraná y sus afluentes que comprenden los Departamentos de Esquina, Goya, Lavalle, Bella Vista, San Cosme, Iratí, Berón de Astrada, San Miguel e Ituzaingó.

El acceso a la información sobre el estado de las áreas naturales protegidas, así como sobre los monumentos es muy escaso dada la inexistencia de información sistematizada sobre el tema en el sitio web del Instituto Correntino del Agua y el Ambiente.

\section{Provincia de Misiones}

\section{V.1. Los ecosistemas de la Provincia de Misiones}

En Misiones se distinguen dos distritos fitogeográficos de la selva: en primer lugar, la selva propiamente dicha, caracterizada por la presencia de árboles como el palmito, el palo rosa, los laureles y especies de cañas o tacuaras. La selva misionera se caracteriza por tener pisos o estratos bien definidos. A su vez, en el territorio misionero se puede encontrar una prolongación de la Selva Paranaense: la ecorregión Campos y 
Malezales, la cual se caracteriza por vastos pastizales de llanura, apenas interrumpidos por pequeños parches boscosos. ${ }^{12}$

\section{V.2. La Constitución de Misiones}

La Carta Magna de esta provincia se encuentra en vigor desde 1958. Si bien la misma no refiere específicamente a las áreas naturales protegidas, en su artículo 57 manda a dictar leyes entre las que enumera las destinadas a la "1) Conservación y mejoramiento de los suelos, de la flora y de la fauna...”. (inc. 1). A su vez, el artículo 56 menciona al bosque y establece que "será protegido con el fin de asegurar su explotación racional y lograr su mejor aprovechamiento social, la ley asegurará la reforestación". Del mismo modo que la Constitución santafesina, podría interpretarse que estos artículos le dan fundamento constitucional al sistema de áreas naturales protegidas.

\section{3. El sistema provincial de áreas naturales protegidas}

Misiones, a través de la Ley XVI - 29 (antes Ley 2932) de 1992 incorpora nueve categorías de manejo:

1) Parques Provinciales: "las áreas terrestres o acuáticas en su estado natural, que tengan interés científico particular o especial atractivo por sus bellezas paisajísticas" (Ley XVI 29, 1992, art. 6). Las áreas se dividen en zonas intangibles y restringidas conforme la afectación de parte de actividades humanas.

2) Monumentos Naturales: "los sitios, especies vivas y plantas, ambientes naturales y yacimientos arqueológicos y paleontológicos de relevante y singular importancia científica, estética o cultural, declarados como tales por leyes especiales y a los cuales se les acuerda protección absoluta. Son inviolables, no pudiendo realizarse en ellos actividad

\footnotetext{
12 MATTEUCCE, Silvia D. (2012). Ecorregiones y Complejos Ecosistémicos Argentinos. Orientación Gráfica Editora S.R.L., Buenos Aires.
} 
alguna con excepción de visitas guiadas que garanticen el principio de intangibilidad absoluta, inspecciones oficiales o investigaciones científicas permitidas por la autoridad de aplicación y la necesaria para su cuidado." (Ley XVI-29, 1992, art. 14). Existe un número importante de monumentos naturales en esta provincia: yaguareté, tapir y oso hormiguero (Ley Provincial XVI-22), lobo gargantilla, águila harpía y pato serrucho (Ley Provincial XVI-44), carayá rojo, zorro pitoco, loro charao, maracaná lomo rojo (Ley Provincial XVI56), aguará guazú y tucán grande (Ley Provincial XVI-75), tordo amarillo y yetapa de collar (Ley Provincial XVI-79), pino paraná y palo rosa (Ley XVI-19), chachí bravo de pantano y chachí bravo de la selva (Ley XVI-82), chachí manso (Ley 4186), urunday blanco (Ley XVI- 68), cactus de teyú cuaré (Ley XVI-70), lapacho negro (Ley XVI-91), pindocito y yatay poñi (Ley 4129).

3) Reservas Naturales Culturales: "Son aquéllas en las que se encuentren comunidades aborígenes interesadas en preservar determinadas pautas culturales propias y cuya relación armónica con el medio es necesario garantizar y las que alberguen yacimientos arqueológicos, ruinas jesuíticas o cualquier otra referencia histórica de interés". (Ley XVI-29, 1992, art. 16)

4) Parques Naturales Municipales: "Son aquellos predios de dominio municipal que conservan rasgos naturales de interés educativo y/o turístico, que permitan la subsistencia en zonas urbanas o periurbanas de aspectos naturales dignos de conservarse, y que sean declarados como tales por las autoridades pertinentes”. (Ley XVI-29, 1992, art. 21)

5) Reservas Privadas: "Se entiende por el área de dominio de particulares, con elementos naturales o culturales con valor de conservación que, mediante convenios especiales con la autoridad de aplicación, pasen a integrar el Sistema de Áreas Naturales Protegidas dentro de los principios establecidos en este Capítulo" (Ley XVI-29, 1992, art. 23) 
6) Reservas Ícticas: "Es todo ambiente acuático que constituye zona de cría o de desove, de concentración de cardúmenes, singularmente calificados para estas finalidades $\mathrm{y}$, en su caso, a aquellos ambientes otros que se consideren especialmente merecedores de protección por sus valores de conservación. Las reservas ícticas están sometidas a regímenes especiales de manejo, pudiendo establecerse vedas parciales o absoluta para la pesca. No puede autorizarse la pesca con redes, espineles u otras artes de pesca masiva, salvo para la pesca científica. Las áreas declaradas como reservas ícticas pueden ser de dominio público o público o privado". (Ley XVI-29, 1992, art. 31).

7) Reservas de Uso Múltiple; Paisajes Protegidos; Reservas Naturales Estrictas: sus descripciones son similares a las plasmadas en la ley de Entre Ríos.

\section{V.4. Territorio protegido}

Misiones cuenta con una superficie total de 3.000.000 has y se destaca por destinar alrededor de 1.394 .000 has a áreas naturales protegidas, convirtiéndose en la provincia de Argentina que mayor porcentaje de su superficie ha protegido mediante estas herramientas jurídicas. ${ }^{13}$ Allí se encuentra una de las ecorregiones más biodiversas del planeta así como alrededor del 50\% del total de las especies de Argentina. Misiones conserva el mayor remanente de selva del Alto Paraná, aunque en variados estados de conservación y diversas formas de tenencia de la tierra. La pérdida y degradación de la Selva Paranaense se debe, entre otros factores, a la expansión sin control de la frontera agropecuaria, a la sobreexplotación del bosque, al desarrollo de infraestructura como represas y rutas y, a la caza ilegal de fauna silvestre.

En esta provincia, además del Parque Nacional Iguazú -segundo parque nacional de nuestro país creado en 1934- existen

\footnotetext{
13 Ecología Misiones (2021) Sistemas de áreas naturales protegidas. Disponible en: https:// ecologia.misiones.gob.ar/anp-sistemas-de-areas-protegidas-naturales/
} 
una serie de parques provinciales entre los que se destacan Cruce Caballero, De la Araucaria, De la Sierra, Fachinal, Teyú Cuaré, Esmeralda, Esperanza, Grupo Isla Grande-Iguazú, Guardaparque Horacio Foester, Ingeniero Agr. Raúl Cametti, Guarambocá, Guardaparque Segismundo Welcz, Isla Caraguatay, Moconá, Profundidad, Piñalito, Salto Encantado, Urugua-í, Uruzú, Puerto Península, Salto Encantado, y Yacuy. En calidad de paisaje protegido se encuentra el Lago Urugua-i, Andrés Giai, Cerro Mborore. Como reserva natural cultural se identifica Papel Misionero en tanto reserva de usos múltiples se encuentra el parque ecológico El Puma. En carácter de monumentos naturales se individualiza la Isla Palacio e Ingeniero Florencio de Basaldúa. Finalmente, como reservas ícticas, el parque natural municipal LH Rolon, Amado Bompland, Esperanza Lote C, Salto Kuppers, Tupambaé. Dentro del marco de las reservas privadas se encuentran Aguaraí-mi, Caminos de Yabebirí, Osununú, Aguapey, Curindy, Valle del Arroyo Cuña Pirú, Rincón Nazarí, Akagupy, La Ponderosa, Jaguaroundí, Rubichana, Arira í.

\section{Conclusiones}

Mediante este artículo quisimos esquematizar la situación regulatoria actual de las áreas naturales protegidas en parte del litoral argentino a modo de aporte del escaso desarrollo existente en la materia dentro del marco del derecho ambiental.

Desde un punto de vista constitucional, las cartas magnas que han sido modificadas más recientemente, como es el caso de Corrientes y Entre Ríos, ya asumen de modo explícito la tutela de la biodiversidad o bien propician la generación de áreas naturales protegidas. En el caso de Santa Fe y Misiones, su texto es más alineado a la lógica de explotación racional de los recursos naturales. Esto es propio de un contexto de época, aunque, cabe señalar, con posterioridad han ido desarrollándose miradas más holistas que aparecen con el derecho ambiental y, más recientemente, con los derechos de la naturaleza como nueva forma de pensar y regular la cuestión ecológica. 
En cuanto a la normativa vigente en cada territorio, las cuatro provincias cuentan con leyes provinciales sobre áreas naturales protegidas que permiten su creación, clasificación y tratamiento específico mediante diversas categorías de manejo. Las mismas no son iguales en todas las provincias, aunque este dato per se no significa que ante la existencia de un mayor número de categorías haya un resultado protectorio mayor. Por el contrario, el dato a observar es si la variabilidad de categorías en el territorio implica o no un resultado robusto en términos de tutela de la diversidad de ecosistemas existentes.

Santa Fe destina la menor cantidad de territorio destinado a áreas naturales protegidas. A su vez, la distribución de las mismas permite advertir la existencia de ambientes naturales sub-representados a lo que se suman problemas de control respecto del estado de cada área. En el caso de Entre Ríos, si bien cuenta con una gran cantidad de áreas naturales protegidas, se advierte un control precario por parte de las autoridades con respecto al estado actual de aquellas, convirtiéndose en la principal dificultad a la hora de conocer las áreas naturales entrerrianas. Misiones, por su parte, es la provincia que mayor porcentaje de su superficie ha destinado a proteger mediante estas herramientas jurídicas, aunque aún perviven problemas de control, así como de tensiones y conflictos por los usos de los territorios. La Provincia de Corrientes, aún con pocas categorías de manejo, es la segunda provincia de esta parte del litoral que alberga gran cantidad de áreas protegidas y la mayoría se encuentran en los Esteros del Iberá.

Este breve y esquemático recorrido permite construir una fotografía sobre lo que generalmente se observa al momento de pensar los sistemas de áreas naturales protegidas. Sin embargo, en función de los resultados protectorios y del estado de la biodiversidad no sólo en esta región sino a nivel global, existen propuestas que proponen revisar las regulaciones vigentes y sugerir modificaciones desde perspectivas emergentes en la actualidad. En América Latina los aportes en este camino son 
relevantes en la medida en que se comienza a desenvolver un giro eco-céntrico que se caracteriza por el reconocimiento de la naturaleza como sujeto de derecho. A ello se suman normativas locales y decisiones judiciales que reconocen como tales a ciertos ecosistemas o territorios. En ese sentido, en Colombia, algunos parques naturales han sido declarados como sujetos de derecho recientemente. Entre ellos, el parque nacional Islas de Salamanca, ${ }^{14}$ el parque nacional Los Nevados, ${ }^{15}$ y el parque nacional Complejo de Páramos las Hermosas. ${ }^{16}$

Este reciente y prolífico proceso permite retomar algunas propuestas que, hace algunas décadas ya aludían a la posibilidad de repensar el estatuto jurídico de los espacios en los que se protege la biodiversidad. ${ }^{17}$ En este contexto, una reactualización de los mecanismos legales para la tutela de la diversidad biológica exige un diálogo con los procesos contemporáneos que se están desarrollando al interior del derecho ambiental latinoamericano y que, de diferente modo intentan desmarcarse de la lógica antropocéntrica que permea en gran medida el derecho de la conservación.

\footnotetext{
14 STC 3872/2020 de la Cámara de Casación Civil de la Corte Suprema de Justicia, 18 de junio de 2020.

15 Acción de tutela de primera instancia 73001-22-00-000-2020-000091-00, Tribunal Superior del Distrito Judicial de Ibagué, Sala Quinta de Decisión Laboral, 28 de agosto de 2020.

16 Acción de tutela de primera instancia 73001-22-05-000-2020-00097-00, Tribunal Superior del Distrito Judicial de Ibagué Sala Laboral, 15 de septiembre de 2020.

17 Entre los primeros antecedentes se destaca: HERMITTE, Marie-Angèle (1988) "Le statut de la diversité biologique" en EDELMAN Bernard y HERMITTE Marie-Angèle (comps.) L'homme, la nature et le droit. Christian Bourgois, Paris.
} 


\section{Anexo}

Cuadro comparativo de la legislación provincial por categorías de conservación

\begin{tabular}{|c|c|c|c|}
\hline $\begin{array}{c}\text { Categorías de } \\
\text { conservación } \\
\text { Santa Fe }\end{array}$ & $\begin{array}{c}\text { Categorías de } \\
\text { conservación } \\
\text { Entre Ríos }\end{array}$ & $\begin{array}{c}\text { Categorías de } \\
\text { conservación } \\
\text { Corrientes }\end{array}$ & $\begin{array}{c}\text { Categorías de } \\
\text { conservación } \\
\text { Misiones }\end{array}$ \\
\hline Ley N N 12.175/2003 & Ley N ${ }^{0} 10.749 / 2017$ & Ley No 4.736/1993 & $\begin{array}{l}\text { Ley XVI - No } 29 \\
\text { (antes Ley } \\
\mathrm{N}^{0} 2932 \text { ) /1992. }\end{array}$ \\
\hline $\begin{array}{l}\text { Reserva Natural } \\
\text { Estricta o Reserva } \\
\text { Científica. }\end{array}$ & $\begin{array}{l}\text { Reservas Naturales } \\
\text { Estrictas }\end{array}$ & & \begin{tabular}{|l} 
Reservas \\
Naturales \\
Estrictas
\end{tabular} \\
\hline Parques Provinciales. & Parques Naturales & \begin{tabular}{|l} 
Parque \\
Provincial
\end{tabular} & \begin{tabular}{|l|} 
Parques \\
Provinciales
\end{tabular} \\
\hline $\begin{array}{l}\text { Monumentos } \\
\text { Naturales }\end{array}$ & $\begin{array}{l}\text { Monumentos } \\
\text { Naturales }\end{array}$ & $\begin{array}{l}\text { Monumentos } \\
\text { naturales }\end{array}$ & $\begin{array}{l}\text { Monumentos } \\
\text { Naturales }\end{array}$ \\
\hline $\begin{array}{l}\text { Reserva Natural } \\
\text { Manejada o } \\
\text { Santuario de Flora y } \\
\text { Fauna. }\end{array}$ & & Reserva natural & \\
\hline Paisaje Protegido & Paisajes Protegidos & & \begin{tabular}{|l|} 
Paisajes \\
Protegidos \\
\end{tabular} \\
\hline $\begin{array}{l}\text { Reservas Naturales } \\
\text { Culturales }\end{array}$ & $\begin{array}{l}\text { Reservas Naturales } \\
\text { Culturales }\end{array}$ & & \begin{tabular}{|l} 
Reservas \\
Naturales \\
Culturales
\end{tabular} \\
\hline $\begin{array}{l}\text { Reservas Privadas de } \\
\text { Uso Múltiple. }\end{array}$ & $\begin{array}{l}\text { Reservas de Usos } \\
\text { Múltiples }\end{array}$ & & $\begin{array}{l}\text { Reservas de Uso } \\
\text { Múltiple } \\
\text { Reservas Privadas }\end{array}$ \\
\hline \multicolumn{4}{|l|}{$\begin{array}{l}\text { Reservas hídricas o } \\
\text { humedales }\end{array}$} \\
\hline & Reservas ícticas & & \\
\hline & & & $\begin{array}{l}\text { Parques Naturales } \\
\text { Municipales }\end{array}$ \\
\hline
\end{tabular}

